\title{
Crisis of the city as an idea on the example of structural transformation of housing development. Urban agriculture as an antidote for suburbanization
}

\author{
Justyna Kleszcz ${ }^{1, *}$ \\ ${ }^{1}$ Department of Architecture and Urban Planning, Faculty of Civil Engineering, Architecture and \\ Environmental Engineering, University of Zielona Góra, ul. Szafrana 1, 65-516 Zielona Góra, Poland
}

\begin{abstract}
The paper aims to present the phenomenon of transgression of contemporary urban living space as the main manifestation of the crisis of urbanity idea through forming new spatial units defining the city in relation to extra-urban functions. Due to the rapidly progressing process of urbanization, cities are beginning to occupy every available space in large parts of the world. That is why the idea of a closed city is becoming rapidly outdated, and open forms adopted by them and connected with the rural landscape have caused the problem of defining a new concept of contemporary urban-rural space. Although often reasons for this phenomenon are seen only in the progressing suburbanization interrupting the continuity of urban structures, this problem is much more complex and related to the search for an alternative to the outdated form of the city. The paper includes an analysis of the phenomenon, one of the manifestations of which is the emergence of downtown and suburban housing estates that combine urban features with food production. Examples of implementation illustrate the analysis of transformations, which gave rise to the new idea of urban living. The designed estates are both an element disrupting the city's dense tissue, but also becoming a determinant of the next level of self-sufficiency of urban inhabitants both structural, functional, energetic and also nutritional from potentially adverse external conditions.
\end{abstract}

\section{The beginning}

According to generally accepted knowledge, suburbanization is one of the forms of spatial development of cities in the so-called model of the city's life cycle, a process characterized by the transfer of urban forms of land development and lifestyle into rural areas and consequently on dynamic, and usually spontaneous, transformation of settlement structures in rural areas that are located within the city's impact zone by introducing elements of the

\footnotetext{
* Corresponding author: j.kleszcz@aiu.uz.zgora.pl
} 
typical urban functional model, related to the land development structure, building intensity, etc., which results in urban sprawl of cities with high impact potential [1].

Investment pressure, exerted on areas directly adjacent to the city, currently causes a number of unfavorable spatial phenomena that creates the overall picture of processes related to decentralization of the city and, in a large simplification, duplicates in a more uncoordinated form typical urban structures in areas not yet adapted to it, with duplicating functions, inhabitant's spatial behavior and their lifestyle. This results in creating areas of spatial chaos at the interface of traditional forms of rural development with "transplanted" urban forms of living.

The paper aims to present possibilities offered by the research (often so far theoretical) and the implementation of alternative forms of urban development, which aims to reconcile the needs of residents of new suburban settlements with the attempt to preserve traditions of the place where they arise. Creating an alternative form of development of housing estates which are not only suburban bedroom areas, but proposing a new housing model, becomes a basic issue to prevent negative effects related to the process of urban sprawl on rural areas. Therefore, the text is to analyze the ways of creating a new model of life in suburban areas combining urban and rural character, thus creating a new value in the urbanized landscape.

\section{Redefining the city}

Nowadays, there is a departure from the historically fixed definition of the city, as: "(...) a historically formed type of settlement, determined by the existence of specific partial community, focused on a certain area, with a separate form of organization, recognized and defined legally and producing as part of its activity a set of permanent material devices with a specific physiognomy that reflects a distinct type of landscape (...)"[2].

In this way a contemporary city can be defined in the context of historically consolidated urban policy as a compact structure dominated and created by only one species - human, and adapted to its habitat needs. In this perspective, modern cities are becoming the expression of primal interspecific competition for the habitat areas between man and the rest of the living nature. Such an approach causes nature degradation occurring in cities to a level that makes it useful for humans, leaving no space for ecological niches, which significantly contributes to the depletion of natural environment of larger and larger areas. The significance of this concept, however, is changing along with the growing level of global urbanization.

The division into traditional functional cities and rural areas resulted from the historical conditions associated with the necessity of grouping space related to agricultural production and ensuring the economic, commercial and, in longer term, also political, administrative and cultural security [3]. The idea of city zoning also sustained this principle.

A significant part of the reasons why urban zoning was adopted in the past was due to the necessity of rational approach towards space requirements and limiting the significant nuisance of some functional areas for urban inhabitants, environmental degradation related to produced pollutants, and certain specific infrastructure requirements in cities ensured only by point (such as rail availability, import of natural resources, etc.). It was also connected with the fact that urban areas did not occupy such large areas as now, thanks to which the distances covered by the inhabitants were strictly limited. Nowadays, however, in the era of the existence of world regions with the level of urbanization reaching almost $100 \%$, staying at the stage of urban zoning of agglomerations and metropolises and attempting to protect the airtightness of urban functions seems to be a significant anachronism. 
The ultimate and, at the same time, the extreme proof that the historical model of the city has become obsolete on many fields, including primarily physical, social and cultural, is the development of the idea of the city genesis in terms of zoogeography. While the attempts to explain the genesis of the city, as a result of logical cause and effect, which was based on the need to ensure security against surrounding nature, other people, in the subsequent stages more and more clearly formalized and codified, treats cities only as anthropogenic, hermetic islands; $;$ new concepts are trying to significantly broaden the analyzed scope of impact of urban space and foundations of its creation. According to Philo [4], the significant role of animals in the historical isolation of urbanized from rural areas was associated with man's efforts to reduce the psychological pressure exerted by the proximity of places of animal killing. This issue is also related to the process of forming another field of knowledge, that is urban zooecology, perceived in the context of a more sublime form of urban ecology and sustainable development policy which can be implemented once a basic level of understanding is reached regarding selected physical parameters of the urban environment [5]. Further discussion on the topic can be found in the author's earlier works referring to the issue of transgression of contemporary concepts of urban planning [6].

\section{New concepts of contemporary urban planning}

As the basic urban function remains human habitation, transformations of the city structure will be most visible in the context of changes in defining and forming housing development in various scales - from urban planning to changing the approach towards architecture of individual buildings. A number of emerging concepts trying to define these forms of presence of nature in the city that connect them directly with the life zone are those areas of design that are the subject of greatest transformation not only of its form, but above all of the ideology of their creation.

Issues related to the emergence and inclusion in the urban design process and significantly expanding the concept of urbanism itself broadens the scope of urban design concepts. The combination of elements previously treated separately - urban and rural planning, landscape design etc. resulted in creating the concept of urban space as a new value. Issues described below can be divided into three basic groups due to the scale and level of impact on those related to the introduction of a new urban function - agriculture, transformations of the city structure and creation of new types of urban landscapes, as well as depending on the scale of impact on concepts relating to separate housing estates, cities or agglomerations, as discussed below.

\subsection{Agriculture as a part of urban planning}

\subsubsection{Agrihood}

The concept derives from the combination of two ideas - agriculture and neighborhood, signifying both - a new social phenomenon occurring in urban residential areas and a modern trend for creating fashionable living space in cities. The phenomenon itself has not been clearly defined and examined so far, which also results in the lack of an unequivocal definition of the form. Although the name has already been accepted by professionals, there is still no unambiguous research on this issue. The size, spatial form, socio-economic background of all types of buildings referring to the term of agrihood are extremely different [7]. Travers draws attention to the fact that such settlements are located both in rural, suburban and metropolitan areas, not only around existing and working farms, but also on post-industrial sites, wastelands, protected natural areas, etc. The ambiguity of the currently used definition is evidenced by the statement made by one of the founders of 
the first agricultural areas in the US agrihood housing estate, Daaron Joffe, describing it as: „(...) an agrihood is a working farm that's really connected to the residents, the local community outside the neighborhood, and connected to the larger region and foodshed (...)" [7]. This slogan has become an important attractor for future residents, especially in the USA. The sign of this has become, among others, an attempt to legally protect the idea by a trademark. The idea was carried out by the Californian development company Rancho Mission Viejo in relation to the newly founded Esencia housing estate. The method of verifying the veracity of statements used by developers of this type of settlements in order to increase interest in real estate sales is to analyze the structure of public and private greenery in those areas, taking into account agricultural land and real costs of its maintenance. As it has been partially demonstrated, this cost does not exceed the value for typical public greenery in comparable, by size and function, settlements. As shown by the research conducted for American conditions, the cost of development and maintenance of green areas designed as raised beds is in fact comparable to the typical form of development [8].

The first attempt at defining the term was made by the Urban Land Institute in 2016, referring it as one of the forms of buildings created at the interface between food and residence. The agrihood was defined as "(...) a single-family, multi-family or multifunctional community built around and strongly focused on an existing working farm. (...) "[9]. At the same time with the concept of agrihood, this systematics provided the basis for determining spatial phenomena such as food-oriented housing estates, a new generation of urban open-air markets, multi-functional and recreational buildings with farming functions, food nodes and culinary incubators etc. These definitions do not reflect, however, the complexity of phenomena related to creating urban communities based on the relationship between human habitation, nature and agriculture. Therefore, there is a need to determine this concept more comprehensively.

The agrihood-like neighborhood unit combines a typical, mostly suburban form of development, with green areas for cultivation and animal breeding, which is intended to enable inhabitants to provide at least partial food independence and to become an element of an integration process. Agrihood is a kind of a housing community that combines largescale agricultural production within the structure of estate, giving a new meaning to the concept of multifunctionality of buildings, because of combining urban and non-urban elements. At the same time, agrihood is a commercial term for housing units built by developers as an implementation of the urban need of social affiliation, carried out by spending free time together on farming for the needs of a given group [10]. Established from the mid-1990s in the USA, such concepts, related primarily to development, based their work on already existing farms in the given area, which, instead of being demolished, were included in the newly designed complex. Often the colloquial definition of this idea is referring to a housing estate - a community built around an existing farm, and most often supported by people employed for this purpose (gardeners, farm workers etc.) [11]. There is a large group of settlements functioning in this way, such as Bucking Horse in Fort Collins, Willsford in Loudoun Country, Hidden Spring in Boise, South Village in Vermont, Praire Commons in Olathe and more.

\subsubsection{Agropolis}

Agropolis, as a spatial concept has its origin in the Latin phrase ager, which means field and the Greek polis - the city. In modern form, the definition was disseminated by L.J.A. Mougeot [12] and refers to the idea of a city of fields and the agrarian city. It is also the name of one of the International Development Research Centre's micro grants, based on the Brazilian economic integration program launched in the 1970s and the transformation of isolated agrovilas into comprehensive local agropoles. In a situation where a typically 
urban structure is subdivided, when due to the phenomenon of urban boundaries spill cease to be continuous and begin to contain discrete, point areas of a different function, most often agricultural or forest, you can no longer speak of a clear division between city and village. This creates the possibility of using those points, so far undeveloped, for the needs of functions that become necessary in a given place just because of the extension of build-in structures. The adoption of such an action model is primarily aimed at reducing limitations resulting from individualization of urban farmers' activities, such as reducing costs of preparing applications for co-financing of individual actions in the process of creating urban agriculture, comparing and assessing system applications, creating a research network and supporting synergistic activities in scientific research over urban agriculture.

After 2005, this concept began to appear in theoretical works on the problem of urban self-sufficiency, especially in areas where it is already a necessity, and not just an opportunity to increase the safety of residents. Khataba (Al Jadida) Agropolis, a concept of a self-sufficient city in the Nile delta developed as a competition designed in 2009 by marcosandmarjan is one of the examples. Due to the rapidly growing number of people living in this area, especially around main cities - Cairo and Alexandria, a large part of them are forced to live on deserted areas in enclosed peripheral satellite settlements - for the rich, or slums for the poor. They all face the problem of rapid increase in demand for food and its rising prices. That is why the proposal called Khataba Agropolis is supposed to concern the creation of not one, but a network of settlements that will also be self-sufficient in terms of food production and electricity, but also serve as a multifunctional structure necessary to function in isolation from the outer areas. The concept assumed a linearcircular layout both for complementary housing and farming.

One of the researchers who used the term agropolis in relation to the broader context of the role of urban agriculture in transforming urban structures was B. Wowrzeczka [13, 14].

\subsubsection{Agroforopolis}

Agroforopolis is a concept taken from the study by Giseke [15] on the morphological types of urban agriculture found in the area of Casablanca. The dominant element of urban structures of this type is the built-up area with separate parts dedicated for cultivation, between which individual farms and small settlements are scattered. As a design proposal, in the original concept, it was used to develop urban agriculture and to integrate development in areas with high forest cover ratio, enabling the preservation of large areas with its natural character.

\subsection{Separation of urban-rural landscape}

\subsubsection{Productive urban landscape}

According to the definition created by Viljoen [16] in 2005, a productive urban landscape is an open area planned and managed in such a way as to become environmentally and ecologically efficient by providing food from urban agriculture, a climate mitigation effect, absorbing pollution and increasing biodiversity by introducing ecological corridors.

\subsubsection{Continuous Productive Urban Landscapes}

The term of continuous productive urban landscape was created as a development of productive urban landscape and as an idea that it should become a combination of urban landscape with a continuous (linear) structure. The concept, also by Viljoen [16], is intended to become a coherently planned and designed combination of both solutions as a form of an opened landscape, as yet unfulfilled. It aims to combine in an urban form all 
aspects of productivity: economic, socio-cultural and environmental, as part of the strategy of urban planning. Designed in a way to enable urban residents to observe all activities and processes traditionally associated with the rural environment, and thus restore the relationship between life and processes necessary to support it.

\subsection{Urban-rural landscape}

New views on the change in defining the city are directly related to the possibility of redefining the idea of urbanism in confrontation with what is non-urban, that is, "rural", rustic etc. An element of this duality is also the change in defining urban landscape and its components. An attempt to determine urban agriculture in a systemic approach has become possible thanks to radical, yet gradually progressing in subsequent cities, change in agricultural policy and crystallization of scientific approach towards this very issue. In the last decade, a number of theories have been developed, providing the basis for analyzing productive urban greenery as a system of related elements that create a dynamic arrangement and form a new type of urban-rural landscape with varying degrees of openness. They consist of groups: from dispersed elements, the so-called picturesque, to a new silhouette of a compact and intensively developed city, in which urban agriculture complements the gap created in the process of increasing compactness of urban tissue with the last, missing function. The very idea of the city is transformed into a specific type of landscape, which is no longer analyzed as a set of individual buildings or even quarters, but as a cohesive (or not) area combined in a formal, functional and ideological way. Some researchers associate this change of approach with the appearance of so-called urban road narration as a consequence of emerging and developing a new, much more common and faster means of transport, and therefore the possibility of observing the city's silhouette from a much wider perspective [17]. In the descriptions of urban space, concepts such as geographical order, volcanic landscape [18], or cityscape have appeared since then [19].

The progressive penetration of urbanized areas and nature takes place along with the development of the form of the in-between city, as a result of blurring boundaries between what is outside and inside of the city structure.

Some researchers even claim that the concept of urban landscape is a direct consequence of this phenomenon of blurring boundaries in the space surrounding humans, between natural and urban [20], proving a close relationship between what we call culture and cultural landscape as a fluid combination of housing and natural production in the city [21]. Other researchers who deal with the issue of urban landscape in the beginning of the 21 st century go a step further. Ipsen and Weichler emphasize the importance of combining the concept of urban planning with nature for the possibility of analyzing the city as a holistic phenomenon. It gives an opportunity to capture the relationship between form, terrain function, lifestyle, cultural patterns and dynamics of ecological systems. This possibility can be applied to the analysis of spatial phenomena of rules governing the environmental analysis of natural landscapes [22]. This is often described as a discourse between natural and cultural landscape, which in general terms are already treated inseparably as individual elements of one compact system [23].

The landscape view and typological division of forms of urban agriculture are new issues. The first attempts to broaden types of emerging landscape were made in the work on guidelines for the development of urban agriculture for the need of District Columbia [24]. This division, however, is more strongly associated with the type of space occupied in micro scale than with a broader approach to the urban context.

The following types of space have been distinguished due to their function: high intensity residential development, commercial, industrial, office and administration, singlefamily housing on small plots, parks and open areas, single-family housing of a residential type (on large plots), and agro-cultural development. 
The first attempts to define the form of urban landscape containing elements of productive greenery took place during the organization of science centers as part of the Urban Agriculture Europe program. Urban landscape patterns of agriculture have been divided due to different scales of interaction between elements: farmland patterns, collective or individual patterns and agricultural spots [25]. This division, however, does not take into account specific types of landscape in a broader context, also outside of architecture, based on the relationship between human and urban environment.

For the first time, this element was included in research conducted by Undine Giseke, showing the relationship between urban landscape, architecture, productive greenery and humans. Based on the research carried out in the region of Casablanca, three levels of activities can be defined, which are taken into account in the process of implementing the concept of urban agriculture as part of synergistic approach to urban planning [15]. This concept assumes dividing urban agriculture into nine basic types of landscape morphology, characterized by compact structure of agricultural space and an open, seminatural landscape. This division, supplemented with forms of urban-rural landscape characteristic for Poland, creates a theoretical basis for the future assessment of conditions of rural-urban landscape in the country [26].

Therefore, an attempt should be made to define a new concept in urban planning regarding the idea of an urban-rural landscape.

The urban-rural landscape is a continuous form within the urban space, characterized by a compact but diverse structure combining urban as well as rural elements permeating and connected by the form of traditional urban greenery. It arises either through layering and merging values and features of urban, rural and natural landscape, or as an autonomous development of urban landscapes by introducing into their structure new forms of development related to agricultural production. Depending on the type of occupied space, climate in which it arises and cultural traditions of forms of urban agriculture or urban greenery structure, it will assume different forms characteristic for a given region.

A different and characteristic form that is becoming a part of cities of European and North American regions is the emergence and development of urban unit emerging as a new idea foundation from scratch, combining urban and rural elements within the structure of housing estates. Agrihood systems are a new spatial form combining set of features usually reserved for each type, created in a targeted and planned form. The element of agrihood landscape, although characteristic, is in fact a combination of most of the aforementioned elements.

The general characteristics of morphological types of the urban-rural landscape in the development of typology proposed by Giseke and supplemented with elements characteristic for the landscape of Polish cities are summarized below:

Precise Urban Agriculture (A) is a form that integrates small-scale agricultural production in a compact and intense urban development, transforming areas of monofunction into multifunctional architectural structures, creating small - scale patchworks. In this type, the dominant type of crop is soilless agriculture, both permanent and temporary. It has the right potential of creating greenery on atypical places such as roofs, walls, vacant lots, urban wasteland, etc.

Beautiful Productive Greenbelt (B) takes the form of multifunctional open space associated with the occurrence of water resources in the city. It is relatively large / long green area that is in close relation to dense urban structures. Based mainly on soil-based farming, it is closely related to the occurrence of other forms of urban greenery, creating a visual division between urban and rural part of landscape components.

Parasitic Backpack Agriculture (C) is characterized by small and large scale farm production mainly of industrial type, based on integration within architectural structures, which are mainly embedded elements. It is an element of future network systems of urban food production. 
Rurban stripes (D) are mix of urban and rural structures at the outskirts of areas of intense urbanization, using the potential of being transformable into other urban functions, mainly as land reserve for future development of the city center. Therefore, land use in the area of this type of landscape occurs mainly temporarily in soil-based farming, forming medium-scale patchwork structures intended as one-family units.

Rurban points (E) constitute a mix of urban and rural structures on the outskirts of areas of intense urbanization, similarly as previously used temporarily and constituting a land reserve for future development in a dispersed form, but still at a short-walking distance.

Rurban Microfabrics (F) assume a cluster form of urban development without a strictly defined center. Their internal structure resembles typically urban with mixed intensity. It mainly uses the type of traditional soil-based urban agriculture, with production directed to local markets in small traditional patchwork farms.

Open-Close Patchwork $(\mathrm{G})$ is characteristic for cities of Central and Eastern Europe and is associated with the occurrence of allotment gardens in the urban tissue. Its form is caused by small and medium-sized areas in centers and downtowns designated for traditional soil-based farming, most often in small plots of land, very rarely - in larger areas. Depending on the current state of regional law, these areas are either excluded from traditional use (closed spaces) or restricted to a wider social group (social gardens).

Country Town $(\mathrm{H})$ is connected with the traditional small-town form constituting regional centers of rural landscape, based on the traditional form of the city center and multifunctional outskirts with more rural character. Occurring on the outskirts of medium-sized housing settlements or large areas used for agriculture with loosely spaced single traditional farms.

Agroforopolis (J) defines the main role of the zone as enriching the urban-rural structure by mixing with agroforestry, creating agricultural patchwork structures as lee space for urban elements, but also forest greenery as a buffer for each - urban and rural parts, which in the long term enables slow mutual transformation of zones and creating a mediumsized or large three-element patchwork structures (urban planning agriculture - forestry).

Beautiful Productive Landscape $(\mathrm{K})$, whose main role is to strengthen socio-economic and spatial synergies by relating urban structures with agriculture and tourism, locates rural activities in an attractive, open landscape in close connection with urban structures and linking urban agriculture with leisure, recreational land use. It causes forming of small scale structures, mainly used by individual families, as its creation is conditioned by the existence of attractive landscape components such as rivers, lanes, hills etc.

Hyper-productive Rural Landscape (L) is created thanks to inclusion of very intensive, mainly soil-based farming in close relation with urban structures to increase the efficiency of short-term supply of fresh, unprocessed food on a larger scale, which is more important in metropolitan areas. The cultivated crops are mainly soil-based, requiring highly developed agriculture and cause the creation of large scale areas that cluster agricultural functions.

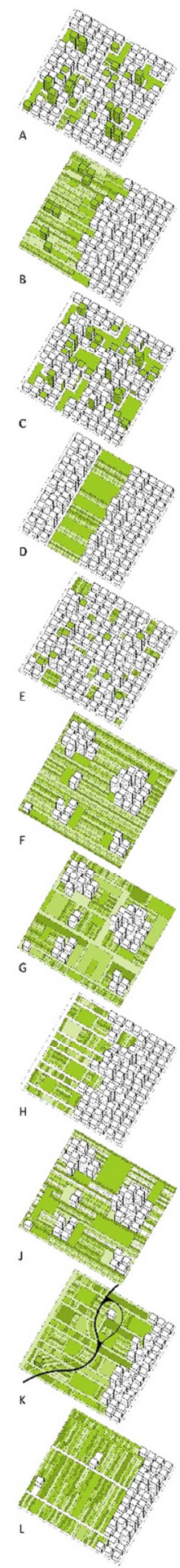

Fig. 1. Morphological types of agri-urban landscapes 


\section{Summary and conclusions}

As shown by the analysis, the currently observed crisis of the idea of the city, as a place to live, has caused a rapid search for alternative solutions that can transform already existing urbanized areas into a place that fulfills all physiological and higher-order needs. Including, as a permanent element, functions related to agriculture and forestry, causes the city's concept itself to change as a compact structure. The result is the crystallization of new urban landscape concepts, combining elements that are built, natural and open, but created by mankind. Giving functionality to all spaces inside of such a system will lead to creating friendly structures for all living organisms, while not increasing the areas nowadays occupied by cities.

The described morphological types of the urban-rural landscape show a very large diversity in terms of possibilities they create in transforming structure of modern cities for the needs of changing social, spatial and cultural conditions. Still regarded as alternatives; discussed in the paper, forms of development have a large potential in improving the existing spatial situation resulting in the improvement of living conditions of urban residents. In terms of ease of implementation, the greatest potential can be found in creating Precise Urban Agriculture or Parasitic Backpack Agriculture landscapes in the event of transformations in city centers, due to the much greater flexibility resulting from forming agricultural zones on a smaller scale and with a greater degree of diversity of all nonobvious fragments of space. In case of smaller cities or strongly developed peripheral zones of agglomerations, the solution that shows the greatest potential for smooth entry into different types of space and local communities functioning is the Rurban Points landscape. Due to the possibility of using smaller or larger clusters of existing buildings of a rural character, it allows for the most efficient use of the potential of urban sprawl in suburban areas for the purpose of creating a new quality of life.

Although the discussion on creating urban-rural landscapes on a global scale remains in most cases only theoretical so far, solutions in the scale of individual settlements are already being implemented. The potential of agrihood, especially if created in conjunction with the planned, conscious design of them as elements of urban-rural landscapes, enables the gradual transformation of individual elements of urban space so that in the future we can bring the image of the city closer to the vision of a sustainable living environment represented by theoretical solutions discussed in the paper.

\section{References}

1. A. Lisowski, M. Grochowski, Procesy suburbanizacji. Uwarunkowania, formy i konsekwencje, (Ekspertyzy do koncepcji przestrzennego zagospodarowania kraju 2008-2033, 2009)

2. K. Dziewoński, Przegląd Geograficzny 28 (4) (1956)

3. J. Kleszcz, , Budownictwo i Architektura, 18(2), 1-10 (2018)

4. Ch. Philo, Animals. (Geography and the City: Notes on Inclusions and Exclusions, Environment and Planning D: Society and Space, 655-681, 1995)

5. L. Pulido, Rethinking Environmental Racism, 12-40 (2000)

6. J. Kleszcz, A,Urban Development Issues, 54, 15-26 (2017)

7. J. Travers, Growing Agrihoods: The Next Frontier in Urban Revitalization (2017), http://civileats.com/2017/01/30/growing-agrihoods-the-next-frontier-in-urbanrevitalization/ [accessed 01.04.2018]

8. B. Anderson, Food Adds Flavor (and Value) to Real Estate: "Agrihoods" and Other Food-based Concepts, UrbanLand (2016), https://urbanland.uli.org/sustainability/food- 
adds-flavor-value-real-estate-agrihoods-food-halls-food-based-concepts/ [accessed 01.04.2018]

9. Urban Land Institute, Cultivating Development: Trends and Opportunities at the Intersection of Food and Real Estate, 3, 46 (2016)

10. M.B. Albright, It's a beautiful day in the Agrihood (2014), http://theplate.nationalgeographic.com/2014/06/23/its-a-beautiful-day-in-the-agrihood/

11. S. Bady, Agrihoods-communities centered around working farms-are attracting homebuyers with a keen interest in fresh, local food. (2017) https://www.probuilder.com/back-land \{accessed 01.04.2018\}

12. L. Mougeot, (Agropolis. The social, political and environmental dimentions of urban agriculture, XII, 2005)

13. B. Wowrzeczka, Architectus, 1(37), 67-80 (2014)

14. B. Wowrzeczka, Architectus, 3(39), 85-95 (2014)

15. U. Giseke, C. Kasper, M. Mansour, Y. Moustanjidi, Nine urban - rural morphologies, Urban Agriculture for Growing City Regions. Connecting Urban - Rural Spheres in Casablanca, 325-326 (2015)

16. A. Viljoen, K. Bohn, J. Howe, (Continuous Productive Urban Landscapes: Designing Urban Agriculture For Sustainable Cities, xviii, 2005)

17. L. Nyka, Czasopismo Techniczne, 109 (1-A/2), 50 (2012)

18. A. Vidler, (Warped space. Art, Architecture and Anxiety in Modern culture, 66-67, 2000)

19. K. Christiaanse, (Urban Development a Landscape, Changing Places, Contemporary German Landscape Architecture, 51, 2005)

20. M. Kuhn, (Cultural landscapes as protagonists' landscapes, Contemporary German Landscape Architecture, 120, 2005)

21. H. Kuster, (Cultural Landscapes. An introduction, Cultural Landscapes and Land Use. The Nature conservation - Society Interface, 1-13 (2004)

22. D. Ipsen, H. Weichler, (Landscape Urbanism, Monu 2- Middle class urbanism, 01, $42(2005)$

23. M. Dieterich, J. van der Streeten, (Cultural Landscapes and Land Use. The Nature Conservation - Society Interface, 2004)

24. H.B. Lanarc-Golder, (The Urban Farming Guidebook. Planning for the Business of Growing Food in BC's Towns \& Cities, 16-17 (2003)

25. S. Paradis, A. Cieszewska, A. Tóth, I. Šuklje-Erjavec, (Agriculture in Urban space, Urban Agrriculture Europe, 120-125 (2016)

26. J. Kleszcz, (Urban agricultural landscapes of Polish cities on selected examples - the introduction, 17th International Multidisciplinary Scientific Geoconference SGEM 2017. Nano, Bio, Green and Space - Technologies for Sustainable Future. Conference Proceedings, 17(63), 1095-1102, 2017) 